\title{
Awareness and Willingness to Pay for Community-Based Health Insurance Scheme among Patients: A Case Study of the Orthopaedic Unit of Murtala Mohammed Specialist Hospital Kano, Northwest Nigeria
}

\author{
Saddiq Shuaibu Abubakar ${ }^{1}$, Jalal-Eddeen Abubakar Saleh ${ }^{2 *}$ \\ ${ }^{1}$ Public Health Department, Kano State Ministry of Health, Kano State, Nigeria \\ ${ }^{2}$ Communicable and Non-Communicable Diseases Cluster, World Health Organization, Kano, Nigeria \\ Email: ${ }^{\star}$ drjadeen@gmail.com
}

How to cite this paper: Abubakar, S.S. and Saleh, J.-E.A. (2021) Awareness and Willingness to Pay for Community-Based Health Insurance Scheme among Patients: A Case Study of the Orthopaedic Unit of Murtala Mohammed Specialist Hospital Kano, Northwest Nigeria. Open Access Library Journal, 8: e7149.

https://doi.org/10.4236/oalib.1107149

Received: January 13, 2021

Accepted: June 20, 2021

Published: June 23, 2021

Copyright $\odot 2021$ by author(s) and Open Access Library Inc.

This work is licensed under the Creative Commons Attribution International License (CC BY 4.0).

http://creativecommons.org/licenses/by/4.0/

\begin{abstract}
Background: Globally, there are about 1.3 billion people without access to adequate health care because of weak health care financing systems. Literature has shown that $13 \%$ (approximately 44 million) of households face financial catastrophic health care costs in any given year and 6\% (approximately 25 million) are pushed below the poverty line. While donor funds have made a significant contribution to improving health care services in many African countries-especially for malaria and HIV/AIDS-the need for additional domestic sources of finance remains a priority, if health systems are to be sustainable. Community-Based Health Financing scheme is an alternative mechanism to providing access for the poor, unemployed and those living in the rural areas; most of who are not under the NHIS nor any private health insurance scheme that could provide financial protection against illness. Since CBHF has proven to be an attractive option in funding the health systems of most developing countries, there is need to scale-up the community-based health financing scheme in Nigeria. Methods: This cross-sectional descriptive study was conducted at the orthopaedic outpatient clinic of Murtala Muhammad Specialist Hospital (MMSH) Kano, northwest Nigeria. Using a total of 260 closed- and open-ended interviewer/self-administered questionnaire on patients between the ages of $18-80$ years of age excluding those with emergencies, the sampled data were analyzed using the statistical package for social sciences (SPSS version 21) and presented using tables and charts with the aid of Microsoft excel. Results: The analyses show that out of a total
\end{abstract}


260 responses collated 221 (85.0\%) were females and 39 (15.0\%) were males. Furthermore, the analyses show that out of the 260 responses, only 98 (37.8\%) were aware of the community-based health insurance scheme. The willingness to pay for community-based health insurance scheme shows a sizeable 34 (13.1\%) only willing to pay for the scheme. Conclusion: This study underscores the need to promote community-based health insurance (CBHI) scheme and encourage more people to participate. This approach would ensure that health care is accessible to all and sundry. However, this can only be possible through a robust awareness plan and public enlightenment about its merits especially in the rural areas to dispel false rumors about the CBHI.

\section{Subject Areas}

Public Health

\section{Keywords}

Community-Based Health Insurance, Willingness To Pay, Universal Healthcare Coverage, Health Financing, Out-of-Pocket Payments, Kano, Nigeria

\section{Introduction}

\subsection{Background}

Health systems in many low-and-middle-income-countries (LMICs) are funded primarily through out-of-pocket (OOP) payments [1] [2]. OOP payments are one of the most inequitable forms of health financing [3]; they act as a barrier to access, contribute towards household poverty, generate little revenue (usually around $5 \%$ of facilities' budget), and promote perverse incentives, bureaucracy and corruption [3] [4] [5] [6]. About 1.3 billion people worldwide do not have access to adequate health care because of weak health care financing systems [7]. An analysis of 116 household expenditure surveys in 89 countries established that 13\% (approximately 44 million) households faced financially catastrophic health care costs in any given year and 6\% (approximately 25 million) are pushed below the poverty line [2]. In addition to OOP payments, African health systems rely heavily on donor funds. Health systems can be destabilized by sudden reductions in donor funding and a heavy reliance on such funding undermines resilience of domestic health systems. While donor funds have made a significant contribution to improving health care services in many African countriesespecially for malaria and HIV/AIDS—-the need for additional domestic sources of finance remains a priority, if health systems are to be sustainable. Community-based health financing scheme is an alternative mechanism to providing access for the poor, unemployed and those living in the rural areas; most of who are not under the NHIS nor any private health insurance scheme that could provide financial protection against illness. Since CBHF has proven to be an attractive option in funding the health systems of most developing countries [7], 
there is need to scale-up the community-based health financing scheme in Nigeria.

\subsection{Purpose}

The overall purpose and intention of this study is to look at the awareness of patients to "community-based healthcare financing" as an alternative for financing health care. In Nigeria, access to health care services is beyond the reach of a common man and statistics shows $70.2 \%$ of people living below the poverty line of USD 1.00 per day which encourages the vicious cycle of poverty, ignorance and disease [8]. The outcome of this study will make recommendations on the need to develop and implement community-based health insurance scheme.

\section{Data Collection and Analysis}

The study population is patients attending orthopaedic outpatient clinic at Murtala Muhammad Specialist Hospital irrespective of their presenting problems and part of the population isolated to represents the whole patients attending the clinic at the time of this research study.

Using a random sampling approach, data was obtained from a cross-section of patients attending orthopaedic outpatient clinic at Murtala Muhammad Specialist Hospital between October and November 2015. The sample size was estimated using Fishers' formula [9] with the level of precision to be $81 \%$, confidence interval of $95 \%$ and the population been heterogeneous.

$$
N=Z^{2} p q / d^{2}
$$

where $N=$ desired sample, $Z=$ standard normal deviation set at $95 \%$ confidence interval i.e., 1.96, $P=$ proportion of individuals known Prevalence of willingness to pay for community-based health care financing in urban areas i.e., $81 \%$ from previous study.

$$
q=1-p=1-0.81=0.19
$$

$d=$ probability of making type 1 error/sampling error $=5 \%$ or 0.05

Therefore:

$$
\begin{aligned}
N & =\left(1.96^{2} \times 0.19 \times 0.81\right) / 0.05^{2} \\
& =236.488896 \\
& =236.49
\end{aligned}
$$

The minimum sample size required is 236.49 . However, $10 \%$ were added for accuracy and non-response.

Thus, the study distributed 260 closed- and open-ended interviewer/self-administered questionnaire to patients between the ages of 18 - 80 years of age excluding those with emergencies. The questionnaire was adopted from some similar studies on Willingness to pay for health insurance in economies similar to that of Nigeria [10] [11] [12]. The data was analyzed using the statistical package for social sciences (SPSS version 21) and presented using tables and charts with the aid of Microsoft excel. 


\section{Results}

The analyses show that out of a total 260 responses collated 221 (85.0\%) were females and 39 (15.0\%) were males (Figure 1).

The mean age distribution of respondents was $42 \pm 12.90$ with majority 78 (30\%) in the range of 30-39 (Table 1 ).

Similarly, $156(60 \%)$ had formal education at various levels and the remaining 104 (40\%) had no formal education (Table 2).

The average monthly income of respondents was $\mathrm{N} 10,007 \pm 5870(60.0 \pm 36.4$ USD), with the majority earning between $\mathrm{N} \mathrm{10,001} \mathrm{and} \mathrm{N} \mathrm{20,000} \mathrm{per} \mathrm{month.}$ (Table 3).

Furthermore, the analyses show that out of the 260 responses, only 98 (37.8\%) were aware of the community-based health insurance scheme (Table 4).

Again, looking at willingness to pay for the community-based health insurance scheme, $226(86.9 \%)$ were not willing to pay leaving a sizeable $234(13.1 \%)$ only willing to pay for the scheme (Figure 2).

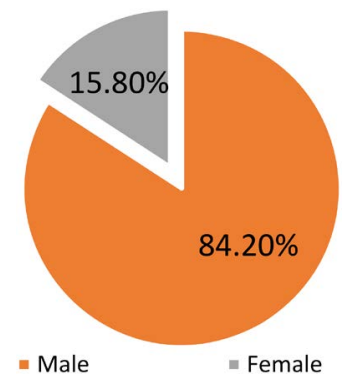

Figure 1. Showing sex distribution of the respondents.

Table 1. Showing age distribution of the respondents.

\begin{tabular}{cc}
\hline Age group & Responses \\
\hline $18-29$ & $41(15.8 \%)$ \\
$30-39$ & $78(30.0 \%)$ \\
$40-59$ & $58(22.5 \%)$ \\
$50-59$ & $42(16.7 \%)$ \\
$\geq 60-\leq 89$ & $41(15.8 \%)$ \\
Total & $260(100 \%)$ \\
\hline
\end{tabular}

Table 2. Showing educational status of the respondents.

\begin{tabular}{ccc}
\hline Educational Level & Frequency & Percentage \\
\hline No Formal & 104 & 40 \\
Quranic & 16 & 6.4 \\
Primary & 56 & 21.7 \\
Secondary & 41 & 15.6 \\
Post-Secondary & 43 & 16.4 \\
Total & 260 & 100 \\
\hline
\end{tabular}


Table 3. Showing monthly income of the respondents.

\begin{tabular}{ccc}
\hline Monthly Income & Frequency & Percentage \\
\hline 5000 & 58 & 22.2 \\
$5001-10,000$ & 112 & 43.4 \\
$10,001-20,000$ & 73 & 28 \\
$>20,000$ & 17 & 6.4 \\
Total & 260 & 100
\end{tabular}

Table 4. Showing the level of awareness of the respondents.

\begin{tabular}{ccc}
\hline Awareness & Frequency & Percentage \\
\hline Aware & 98 & 37.8 \\
Not Aware & 162 & 62.2 \\
Total & 260 & 100 \\
\hline
\end{tabular}

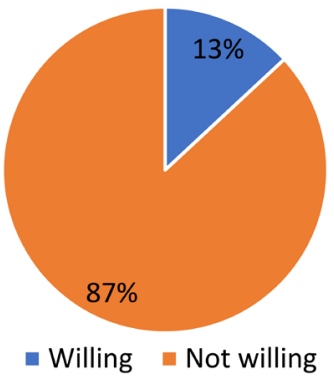

Figure 2. Showing the different patient's response on their willingness to pay for community-based health insurance (CBHI).

Table 5. Showing the relationship between awareness and willingness to join the community-based health insurance scheme.

\begin{tabular}{cccc}
\hline & \multicolumn{3}{c}{ Aware of Community Health Insurance } \\
\hline Willingness to Join & Poor & Fair & Good \\
\hline No (\%) & $226(87.0)$ & $75(85.2)$ & $0(0.0)$ \\
Yes (\%) & $34(13)$ & $13(14.8)$ & $10(100)$ \\
\hline
\end{tabular}

Table 5 shows the relationship between 'awareness and willingness' to join the community-based health insurance scheme. The awareness of respondents about CBHI influenced their willingness to join CBHI and insure all their family members. Those with good awareness were also willing to pay more for CBHI with mean willingness to pay of N740 or $\$ 2.33$; this is statistically significant with $P$ value of 0.00 .

$$
X^{2}=1.732(\mathrm{df}=2, \mathrm{P} \text { value }=0.184)
$$

\section{Discussion}

The findings of this study showed that awareness of CBHI is low (37.8\%), with major source of information being radio (37.8\%). Earlier studies done in rural 
Cameroon found awareness to be $27.07 \%$ [13]. However, a study done in Eastern Nigeria found knowledge of CBHI to be $11 \%$ and another carried out among surgical patients in Niger Delta region of Nigeria revealed an awareness of $3.06 \%$ [14] [15]. These results might be due to the general low level of awareness about health insurance systems. This wide disparity may be because this study was done among patients at Murtala Muhammad specialist hospital. The patients comprised more of less educated and less enlightened people who have less access to information. This was attributed to campaigns in the media as more than half of the respondents in that study said their main source of information was the mass media. Majority of the studied population $(73.3 \%)$, in this study have a poor awareness of understanding of the principles of CBHI. This contrasted with the result from a study conducted among staff of Ministry of health and District health officers in Uganda who had good knowledge of the principles [16]. In a study in Ghana, it was found out that those with good awareness of $\mathrm{CBHI}$ and willing to join $\mathrm{CBHI}$ for their entire family with mean willingness to pay a monthly premium of $\$ 3.03$ [10]. It was observed that awareness of CBHI in rural communities is low and this may be due to a dearth of information and low awareness of CBHI in such communities [17].

\section{Conclusion}

The outcome of this study underscores the need to promote community-based health insurance (CBHI) scheme and encourage more people to participate. This approach would ensure that health care is accessible to all and sundry. However, this can only be possible through a robust awareness plan and public enlightenment about its merits especially in the rural areas to dispel false rumors about the CBHI. It is clear from this study that CBHI is not known across Nigeria because majority of the respondents were not aware and hence not willing to participate in this type of insurance as most believe it is not for profit.

\section{Recommendations}

Based on the outcome of this study, the following recommendations are proffered:

1) Assist LGAs to plan and implement CBHIs, with adequate attention to the costs of service delivery, the ability of the membership to pay premiums, and factors that could promote long-term sustainability

2) Provide technical assistance to LGAs to build local management and technical skills to operate CBHIs.

3) Pass legislation guaranteeing free healthcare for pregnant women and children under age 5 and fund this mandate.

4) Ensure open participation of private healthcare providers and further strengthen involvement of private health facilities as some of the health facilities are only involved in the State Health Insurance scheme on a paper.

5) Help to mobilize and organize communities to implement CBHIs. This could 
be through advocacy to the Kano State Honorable Commissioner for Health and State Legislative Health Committee to present a bill for the establishment of private health insurances including Community Based Health Insurance Scheme to make it open for the community or private entity.

6) Raise budgetary provisions for primary healthcare systems and facilities.

7) Provide technical assistance to communities to build local management and technical skills to operate CBHIs.

\section{Limitations of the Study}

Limited resources and time were the major constraints. Trained interviewers had to be used to facilitate data collection. Lack of health incentives might have contributed to non-responses and willful misstatements.

\section{Data Availability}

All data have been summarized and presented in the manuscript. The data cannot be deposited to any external agency because of policy and other restrictions by the institution.

\section{Ethical Issues/Protection of Participants Rights}

Permission to conduct the study was obtained from the Head of Department of the institution. Informed consent of respondents was sought after confidentiality was guaranteed. The data collected for this study has been cleaned of all identifying personal information. The aim was to eliminate any threat to unauthorized exposure of such information.

\section{Conflicts of Interest}

The authors declare no conflicts of interest regarding the publication of this paper.

\section{References}

[1] Sekhri, N. and Savedoff, W. (2005) Private Health Insurance: Implications for Developing Countries. Bull World Health Organ, 83, 127-134.

[2] Carrin, G., Mathauer, I., Xu, K. and Evans, D.B. (2008) Universal Coverage of Health Services: Tailoring Its Implementation. Bulletin of the World Health Organization, 86, 857-863. https://doi.org/10.2471/BLT.07.049387

[3] Evans, D.B., Carrin, G. and Evans, T.G. (2005) The Challenge of Private Insurance for Public Good. Bulletin of the World Health Organization, 83, 83.

[4] Preker, A.S., Carrin, G., Dror, D., Jakab, M., Hsiao, W. and Arhin-Tenkorang, D. (2002) Effectiveness of Community Health Financing in Meeting the Cost of Illness. Bulletin of the World Health Organization, 80, 143-150.

[5] Poletti, T., Balabanova, D., Ghazaryan, O., Kamal-Yanni, M., Kocharyan, H., Arakelyan, K. and Hakobyan, M. (2007) Options for Scaling up Community-Based Health Insurance for Rural Communities in Armenia. Health Systems Development. London School of Hygiene and Tropical Medicine, London. 
[6] Polonsky, J., Balabanova, D., McPake, B., Poletti, T., Vyas, S., Ghazaryan, O. and Yanni, M.K. (2009) Equity in Community Health Insurance Schemes: Evidence and Lessons from Armenia. Health Policy and Planning, 24, 209-216. https://doi.org/10.1093/heapol/czp001

[7] Adinma, E.D. and Adinma, B.J. (2010) Community Based healthcare Financing: An Untapped Option to Effective Healthcare Funding in Nigeria. Nigerian Medical Journal, 51, 95-100.

[8] WHO (2007) Country Cooperation Strategy: Federal Republic of Nigeria, 2002-2007. WHO, Geneva.

[9] Bamigboye, A.E. (2007) Sample Size Determination: A Companion of Medical Statistics. Folbam Publishers, Samonda, Ibadan, 141-155.

[10] Asenso-Okyere, W.K., Osei-Akoto, I., Anum, A. and Appiah, E.N. (1997) Willingness to Pay for Health Insurance in a Developing Economy. A Pilot Study of the Informal Sector of Ghana Using Contingent Valuation. Health Policy, 42, 223-237. https://doi.org/10.1016/S0168-8510(97)00069-9

[11] Ahmed, S., Hoque, M.E., Sarker, A.R., Sultana, M., Islam, Z., et al. (2016) Willingness-to-Pay for Community-Based Health Insurance among Informal Workers in Urban Bangladesh. PLoS ONE, 11, e0148211.

https://doi.org/10.1371/journal.pone.0148211

[12] Obinna, O., Ekechi, O., Chima, O., Benjamin, U., Joses, K. and Amos, P. (2010) Willingness to Pay for Community-Based Health Insurance in Nigeria: Do Economic Status and Place of Residence Matter? Health Policy and Planning, 25, 155-161. https://doi.org/10.1093/heapol/czp046

[13] Arkin-Tenkorang, D.C. (2001) Health Insurance for the Informal Sector in Africa: Designing Features, Risk Protection and Resource Mobilization, Health, Nutrition and Population (HNP) Discussion Paper. World Health Organization, Washington DC.

[14] Onwujekwe, O., Onoka, C., Uzochukwu, B., Okoli, C., Obikeze, E. and Eze, S. (2009) Is Community-Based Health Insurance an Equitable Strategy for Paying for Healthcare? Experiences from Southeast Nigeria. Health Policy, 92, 96-102. https://doi.org/10.1016/j.healthpol.2009.02.007

[15] WHO (2005) Social Health Insurance: Sustainable Health Financing, Universal Coverage and Social Health Insurance. In: 58th World Health Assembly: 2005. World Health Organisation, Geneva, 1-3.

[16] Basaza, R.K., Criel, B. and Van der Stuyft, P. (2010) Community Health Insurance Amidst Abolition of User Fees in Uganda: The View from Policy Makers and Health Service Managers. BMC Health Services Research, 10, Article No. 33. https://doi.org/10.1186/1472-6963-10-33

[17] Sambo, M.N., Idris, S.H., Bashir, S.S. and Muhammad, J.B. (2013) Financial Hardship in Settling Medical Bills among Households in a Semi-Urban Community in Northwest Nigeria. West African Journal of Medicine, 32, 14-18. 